\title{
Efficient Metal Processing Using High Average Power Ultrafast Laser
}

\author{
John Lopez ${ }^{* 1}$, Konstantin Mishchik ${ }^{* 2}$, Girolamo Mincuzzi ${ }^{* 3}$, Eric Audouard ${ }^{* 2}$, Eric Mottay ${ }^{* 2}$ and Rainer Kling $^{* 3}$ \\ ${ }^{* 1}$ UNIV BORDEAUX, CELIA UMR5107 CNRS CEA, cours de la Libération, 33400 Talence, France \\ E-mail: John.lopez@u-bordeaux.fr \\ *2 AMPLITUDE SYSTEMES, avenue de Canteranne, 33600 Pessac, France \\ ${ }^{* 3}$ ALPHANOV, rue François Mitterand, 33400 Talence, France
}

\begin{abstract}
Nowadays the relevance and the robustness of ultrafast lasers are well established for many industrial applications. Indeed this laser technology combines the unique capacity to process any type of material with an outstanding processing precision and a minimal heat affected zone. The key issue is to combine high throughput, low residual thermal load and good processing quality. Thanks to high average power and high repetition rate it is possible to achieve high throughput providing that the operating parameters are precisely tuned to the application, otherwise heat accumulation and heat affected zone may appear, leading to detrimental effects such as burr, uncontrolled melting and metal oxidation. In this paper we report on high-throughput laser ablation of stainless steel using a $100 \mathrm{~W}-$ and $10 \mathrm{MHz}$ - ultrafast laser. Operating parameters such as fluence, repetition rate and scanning velocity have been considered. Results are discussed in terms of ablation efficiency, surface morphology, multipass and up-scaling capabilities. We observe that pulse-to-pulse pitch and delay are key parameters that must be taken into account in order to define relevant process windows. The use of polygon scanner instead of galvo scanner enables us to reduce the thermal load along the laser trajectory.

DOI: 10.2961/jlmn.2017.03.0020
\end{abstract}

Keywords: femtosecond, picosecond, ablation, stainless steel

\section{Introduction}

Today there is an increasing interest for high throughput surface processing of smart parts for watch industries or large manufacturing tools for injection molding, embossing and printing industries. Such an operation requires to combine high removal rate, high quality issues (low roughness, burr-free, narrow heat affected zone), reliability and high accuracy (tiny spot). Short pulse lasers are commonly used for this application but the main limitation comes from uncontrolled melting of the processed area while using high average power (above $50 \mathrm{~W}$ ). Therefore, the maximum achievable removal rate is about $10 \mathrm{~mm}^{3} / \mathrm{min}$ with this laser technology. In this context, ultrashort pulse lasers seems to be a promising technology since it is potentially possible to overcome this limitation by combining high throughput [1] and outstanding processing quality [2-3] at the same time, providing that the operating parameters are finely tuned to the application in order to mitigate the thermal load into the target material. Furthermore, can we take advantage of new industrial tools, such as high power femtosecond laser [4-7] or high dynamic beam deflector devices [8], to meet the needs of industry?

In the present paper we present some results on high throughput single and multi pass surface ablation of stainless steel using a $100 \mathrm{~W}$ - and $10 \mathrm{MHz}$ - ultrashort pulse laser combined with either a galvo or a polygon scanner. The influence of key process parameters such as fluence, repetition rate and pulse-to-pulse pitch and delay are considered. Correlation between ablation efficiency, multi pass capability and surface morphology are also discussed.

\subsection{Ultrashort pulse ablation}

The ablation mechanism with ultrashort pulses is governed by the laser properties as well as the optical and the thermo-physical properties of the material. This mechanism has been described in several key papers in the last decades [2-3,9-10]. For metals, the absorption generally occurs in free electrons of the conductive band thanks to inverse Bremsstrahlung. This absorption is followed by a fast energy relaxation and thermalization within the electronic subsystem on a femtosecond timescale, then a localized heat diffusion by hot electrons, and finally an energy transfer from hot electrons to the lattice, owing to the photonelectron coupling, on a longer time scale ranging from few picoseconds to few tens of picoseconds depending on the metal [11].

In the middle of the 90's Momma et al. have published very impressive micrographies of stainless steel drilled in the nanosecond, picosecond and femtosecond regimes, showing that ultrashort pulses enable to reduce burr and droplets appearance in the vicinity of the hole [3]. Indeed, thanks to the extremely short pulse duration, the thermal diffusion into the surrounding bulk material is significantly reduced compared to longer pulses, even if some residual heat remains into the target material after laser ablation [12-14].

\subsection{How to scale-up the ablation process?}

The question is how to scale-up the process since there are many parameters with which we can play with. Parameters of influence in surface ablation and their 
process window have been already reviewed and discussed in previous papers [2-3,15-20].

The maximum removal rate achievable is correlated to the average power; therefore there are two options to increase the removal rate, either we play with repetition rate or pulse energy. Since we aim for accuracy we need tiny spot (few tens of microns), then increasing pulse energy leads to increase fluence as well. So let's consider the two options.

\subsection{Using high fluence to scale-up the ablation process}

The first option to improve the removal rate is to increase the fluence. Basically, removal rate normally increases with fluence. Chichkov et al. have shown that in the femtosecond-picosecond range near-threshold fluence leads to a better ablation quality than higher fluence [2]. Indeed, ablation at high fluence increases the thermal load into the target material, and by this mean introduces detrimental side-effects. Therefore, low fluence leads to high processing quality and low removal rate (optical regime), meanwhile high fluence induces poor processing quality and high removal rate (thermal regime). So, is it more relevant for a given pulse energy to use a small spot with high fluence or a large spot with a low fluence? Neuenschwander et al. have recently pointed out an optimum in fluence near the ablation threshold that gives the best specific removal rate [18-19]. This optimum in fluence is shifted to lower fluences for shorter pulse duration. The highest specific removal rate value increases for shorter pulse duration. These points have been confirmed for sub-picosecond pulse duration by Lopez et al. [16-17]. Neuenschwander et al. have also proposed a model to explain these tendencies [18-19]. Furthermore, Lopez et al. have underlined that this effect of pulse duration is material dependent [16-17].

\subsection{Using high repetition rate to scale-up the ablation process}

The second option to improve the removal rate is to increase the repetition rate up to few $\mathrm{MHz}$. However, rising repetition rate from $100 \mathrm{kHz}$ to few $\mathrm{MHz}$ induces two antagonist phenomena: heat accumulation [12-13] on one hand and particles shielding [21] on the other hand. Indeed, heat accumulation enhances the removal rate to the detriment of the processing quality $[16-17,20]$ meanwhile particles shielding reduces the pulse energy available to produce ablation [20].

Particles and plasma shielding may occur if the pulseto-pulse delay is too short with respect to the lifetime of the ablation plume. Indeed, König et al. have used a pumpprobe-based time-resolved plasma attenuation experiment in order to measure the plume lifetime during laser ablation of Aluminum with high repetition rate in the femtosecond regime. With their set of parameters, particles shielding occurs above $200 \mathrm{kHz}$ and plasma shielding above $5 \mathrm{MHz}$ [21].

Heat accumulation occurs when the pulse-to-pulse delay is shorter than the heat relaxation time of the target material [12-13]. Ancona et al. have measured the number of pulses to go through a stainless steel foil with picosecond and femtosecond pulses and with repetition rates ranging from $100 \mathrm{kHz}$ to $1 \mathrm{MHz}$ [20]. The author demonstrates that higher drilling efficiency is obtained for shorter pulses (less pulses are required). Furthermore, in the range of 300 to $500 \mathrm{kHz}$, the heat accumulation induced by high repetition rate becomes sufficient enough to overcome the negative effect of particles shielding and to enhance the drilling rate [20]. The effect of heat accumulation is enhanced with increasing fluence and repetition rate. In the same paper it is shown that the effects of heat accumulation and particles shielding are material dependent; indeed they are less pronounced on Copper with respect to steel [20]. More recently Finger et al. have confirmed the interplay between plasma shielding and heat accumulation in the $\mathrm{MHz}$ regime, and proposed a theoritical model to describe this behavior [22]. Di Niso et al. have also shown that heat accumulation resulting from MHz-repetition rate reduces both ablation threshold and incubation coefficient [23]. Indeed, the author observed that ablation threshold is decreased by a factor of 2 on Steel while the repetition rate rises from 0.1 to $1 \mathrm{MHz}$.

Heat accumulation has also a detrimental effect on surface morphology [14,24]. Due to heat accumulation the offset temperature of the target material rises up to certain limit which depends on target material, on scanning velocity [14] and repetition rate as well [24]. If the offset temperature reaches about $600^{\circ} \mathrm{C}$ to $800^{\circ} \mathrm{C}$ on steel, the surface morphology changes from a smooth, reflective and meltfree surface to a bumpy, dark and oxidized surface.

Neuenschwander et al. have recently proposed different processing strategies to mitigate the negative effects of heat accumulation [24].

Last but not least, Kerse et al. have demonstrated that $\mathrm{GHz}$-intrabursts combined with $\mathrm{kHz}$ bursts reduce the ablation threshold and enhance ablation efficiency of Copper and Silicon [25]. The principle is to apply ultrafast successions of laser pulses in order to ablate the target material before the residual heat deposited by previous pulses diffuses away from the processing region. By this mean, collateral damages are significantly reduced.

To summarize, thermal load may come from high fluence or high repetition rate; both contributes to increase specific removal rate but in the same time may introduce detrimental side-effects. Therefore, it is necessary to identify relevant process windows.

\section{Experimental}

\subsection{Laser source}

All trials on stainless steel have been performed with a commercial Yb-doped solid-fiber hybrid ultrashort laser (Tangor, Amplitude Systemes). The operating wavelength is $1030 \mathrm{~nm}$. The $\mathrm{M}^{2}$ factor is about 1.2 . The maximum average power is $100 \mathrm{~W}$ with a repetition rate ranging from 2 to $10 \mathrm{MHz}$. An internal pulse picker enables to generate lower repetition rates down to $1 \mathrm{kHz}$. The pulse duration is below 500 fs for all repetition rate values. The pulse duration is measured with a Pulse Check autocorrelator.

\subsection{Experimental setup}

The experimental setup includes the following elements: a laser, a halfwave plate combined with a polarizer cube for power tuning, a beam expander, a 2-axis scanner, a 
set of XYZ-stages for focus setting and for positioning the sample under the laser beam, and finally a sample holder. Two different beam deflector devices were used for beam motion on the target. The first one is a galvo scanner (IntelliScan III-14, Scanlab, focal length $100 \mathrm{~mm}$, max. velocity $5 \mathrm{~m} / \mathrm{s}$ ) meanwhile the second one is a polygon scanner (LSE170, Nextscan, focal length $190 \mathrm{~mm}$, max. velocity $100 \mathrm{~m} / \mathrm{s}$ ). The scanning velocities have been checked by measuring the distance between two subsequent spots at low repetition rate $(10 \mathrm{kHz})$. The magnification of the beam expander is $\mathrm{x} 2$ with the galvo and $\mathrm{x} 3$ with the polygon. The average power measurement is made before the beam expander. The optical transmission between the laser output and the target is $90 \%$ with the galvo and 69\% with the polygon. Then the maximum average power available on the target material is about $90 \mathrm{~W}$ with the galvo and 70 $\mathrm{W}$ with the polygon. The polarization is circular with the galvo and linear with the polygon. The spot size (at $1 / \mathrm{e}^{2}$ ) is measured thanks to a WinCam-D beam analyzer. The spot size is $30 \pm 2 \mu \mathrm{m}$ with the galvo and $38 \pm 2 \mu \mathrm{m}$ with the polygon. The fluence is calculated by dividing the pulse energy by the spot area. The resulting fluence has been varied from 0.13 to $24 \mathrm{~J} / \mathrm{cm}^{2}$ with the galvo and from 0.64 to $6.4 \mathrm{~J} / \mathrm{cm}^{2}$ with the polygon.

All collected data take into account only laser pulses that fit into scanning line length; so they don't take into account the loss of laser pulses due to mechanical efficiency, unprocessed area or calculation time of the scanning device. These phenomena reduce the maximum utilization rate [8] of beam deflector device and consequently reduce the time window actually dedicated to the engraving process (50 to $90 \%$ for galvo and 50 to $70 \%$ for polygon).

\subsection{Target material}

Trials have been done on austenitic stainless steel AISI 316L / DIN 1.4404 foils with a thickness of $0.5 \mathrm{~mm}$. These samples were provided from Goodfellow. No pre-cleaning was used prior to laser irradiation.

\subsection{Experimental protocol}

For each set of parameters, in terms of fluence, repetition rate and scanning velocity, we have produced parallel lines with increasing number of laser passes (scans). We have considered 10 levels in fluence for both beam deflector device configurations, 8 levels in velocity for galvo scanner $(0.1,0.25,0.5,1,2,3,4$ and $5 \mathrm{~m} / \mathrm{s}$ ) and 3 for polygon $(25,50$ and $100 \mathrm{~m} / \mathrm{s}), 6$ levels in repetition rate for galvo $(0.5,1,2,4,8$ and $10 \mathrm{MHz})$ and 4 for polygon (2, 4, 8 and $10 \mathrm{MHz}$ ). The spatial overlap between subsequent pulses is ranging from $66.7 \%$ to $99.9 \%$ with the galvo and from $67.1 \%$ to $93.4 \%$ with the polygon.

Each line produces a groove on the target whose depth, width and shape depend on the operating parameters. The number of laser passes varied from 1 to 120 with the galvo scanner and from 30 to 240 passes with polygon scanner. Single pass with a polygon scanner leads to an insufficient groove's depth for a significant depth measurement.

In order to validate the relevance of this experimental protocol we have done the comparison of the removal rate obtained with $2.5 \mathrm{~mm}$-lines (single pass) and with $2.5 \times 1 \mathrm{~mm}^{2}$-cavities (single pass, hatch). The comparison was performed at 9 and $45 \mathrm{~W}$ with a $2 \mathrm{MHz}$ - repetition rate and a $2 \mathrm{~m} / \mathrm{s}$-scanning velocity (Galvo). Both pulse-to-pulse and line-to-line pitch are fixed to $1 \mu \mathrm{m}$ (overlap $96.7 \%$ ). The difference in term of removal rate is below $5 \%$, so the values collected while engraving lines and cavities are quite similar.

\subsection{Sample characterization}

The profile of each groove (depth and width) was measured using a Leica DCM 3D confocal microscope based on LED technology with a 50x/0.90-objective. The cross-section of the groove is calculated using the z-profile by integrating the groove's volume below the mean surface level, which is defined outside the groove area. The most significant measurements were obtained on grooves with depth between 0.3 to $20 \mu \mathrm{m}$, and with aspect ratio below 1 . The width of the groove was ranging from 15 to $45 \mu \mathrm{m}$, depending on the fluence, the repetition rate, the scanning velocity and the number of passes. For groove with aspect ratio above 1 , the roughness and the shape of sidewalls induce light trapping and shadowing effects which reduce the accuracy of the measurement. Furthermore, below 0.3 $\mu \mathrm{m}$ the groove is not deep enough, compared to the initial sample roughness, to get a significant depth measurement. Then, the removal rate is obtained by multiplying the crosssection and the scanning velocity. The corresponding deposited energy can be calculated taking into account the pulse energy and the repetition rate during the same time window.

Scanning electronic microscopy (SEM) analyses were also performed using a Phenom ProX microscope in order to observe the processing quality in the vicinity of the grooves. This SEM microscope offers two modes: the full mode which gives a realistic view of the surface and the topography mode which is more suitable to enhance high and low-relief. The samples have been cleaned in an ultrasonic bath (3 min, water, $30^{\circ} \mathrm{C}$ ) before SEM analysis.

\subsection{Etch rate}

Etch rate is the material removal rate either per pulse or

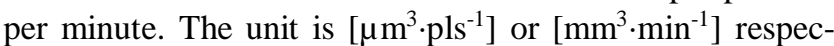
tively. The specific removal rate is defined as the removal rate per watt $\left[\mathrm{mm}^{3} \cdot \mathrm{min}^{-1} \cdot \mathrm{W}^{-1}\right]$.

\subsection{Ablation efficiency}

How to set the operating parameters in order to get the best process in terms of efficiency? To answer this question we introduce the ablation efficiency $(\rho)$ as the ratio between the minimum energy required to transform $1 \mathrm{~mm}^{3}$ from solid to vapor with a calculation based on thermo dynamical laws, called $E_{\text {th }}\left[\mathrm{J} \cdot \mathrm{mm}^{-3}\right]$, and the energy required to engrave a $1 \mathrm{~mm}^{3}$-groove in our experiment, called $E_{\exp }\left[\mathrm{J} \cdot \mathrm{mm}^{-3}\right]$. The formula used for calculation of ablation efficiency is the following:

$$
\rho=\frac{E_{t h}}{E_{\exp }}
$$

$E_{\text {exp }}$ is calculated from our experimental data using the following formula:

$$
E_{e x p}=\frac{P_{a v}}{S \times V}
$$


Where $\mathrm{P}_{\mathrm{av}}$ is the average power on the target [W], $\mathrm{S}$ is the groove cross-section $\left[\mathrm{mm}^{2}\right]$ and $\mathrm{V}$ is the scanning velocity $[\mathrm{mm} / \mathrm{s}]$.

Meanwhile, $E_{\text {th }}$ is calculated by adding melting enthalpy $\left(\Delta \mathrm{H}_{\text {melt }}\right)$, boiling enthalpy ( $\left.\Delta \mathrm{H}_{\text {boil }}\right)$ and the enthalpy required to heat the metal from ambient temperature to a temperature just above its boiling temperature $(\Delta \mathrm{H})$, as exhibited in the following formula:

$$
E_{t h}=\Delta H_{m e l t}+\Delta H_{b o i l}+\Delta H
$$

Where $\Delta \mathrm{H}$ is defined as:

$$
\Delta H=C_{p}(T) \times \Delta T_{\text {Sol } \rightarrow L i q}+C_{p}(T) \times \Delta T_{L i q \rightarrow G a s}
$$

For basic element, the enthalpy $\Delta \mathrm{H}$ can be calculated using the Shomate equation [26]. For alloy, the enthalpy $\Delta \mathrm{H}$ is estimated using the enthalpy of each component weighted according to the relative composition of this alloy, which is about $69 \% \mathrm{Fe}, 17 \% \mathrm{Cr}, 12 \% \mathrm{Ni}$ and $2 \% \mathrm{Mo}$, in case of 316L stainless steel. Data are regrouped in table 1.

Table 1 Theoretical calculation of energy required to vaporize $1 \mathrm{~mm}^{3}$ of selected metals $\left(E_{t h}\right)$

\begin{tabular}{lcccc}
\hline Material & $\begin{array}{c}\Delta \mathrm{H} \\
\mathrm{J} / \mathrm{mm}^{3}\end{array}$ & $\begin{array}{c}\Delta \mathrm{H}_{\text {melt }} \\
\mathrm{J} / \mathrm{mm}^{3}\end{array}$ & $\begin{array}{c}\Delta \mathrm{H}_{\text {boil }} \\
\mathrm{J} / \mathrm{mm}^{3}\end{array}$ & $\begin{array}{c}\mathrm{E}_{\text {th }} \\
\mathrm{J} / \mathrm{mm}^{3}\end{array}$ \\
\hline Steel & 15.4 & 2.2 & 59.6 & 77.2 \\
Iron & 16.9 & 1.7 & 58.6 & 77.2 \\
Chrome & 12.8 & 3.6 & 54.6 & 71.0 \\
Nickel & 15.4 & 2.6 & 65.2 & 83.2 \\
Molybd. & 17.2 & 4.5 & 70.6 & 92.3 \\
\hline
\end{tabular}

The ablation efficiency is a dimensionless ratio. In case of an ideal process, ablation efficiency should be equal to one since all the incoming energy is used for ablation. However, in case of direct laser ablation process, ablation efficiency is generally less than one since part of the incoming energy is spent in particles shielding, light scattering, surface reflection or residual heating [12-14]. On the other hand, other phenomena, such as droplets ejection, spallation or phase explosion may also contribute to material removal and modify the ablation efficiency ratio [27]. So, the ratio $E_{\text {th }} / E_{\exp }$ describes how close to an ideal and efficient process we are. The higher the ratio is the more efficient will be the engraving process. The ablation efficiency can be plotted as a function of fluence, repetition rate, pulse duration energy or dose per millimeter, in order to determine the influence of each operating parameter and their process window [16-17].

\section{Results and discussion}

This paragraph deals with the effect of fluence, repetition rate and number of passes on ablation efficiency of stainless steel. First we present the results obtained with the galvo scanner, with a scanning velocity up to $5 \mathrm{~m} / \mathrm{s}$, and then we present the results obtained with the polygon scanner with a scanning velocity up to $100 \mathrm{~m} / \mathrm{s}$.

\subsection{Ablation efficiency, multipass capability and sur- face morphology with the galvo scanner}

Figure 1 depicts the variation of ablation efficiency versus fluence at $2 \mathrm{MHz}$ and $1 \mathrm{~m} / \mathrm{s}$ in a single pass. The ablation efficiency values obtained at low fluence (below 1.5 $\mathrm{J} / \mathrm{cm}^{2}$ ) are in good agreement with results reported in [1617] as shown in figure 1 . Ablation efficiency is about 0.33 at $0.2 \mathrm{~J} / \mathrm{cm}^{2}$, and then it decreases down to 0.15 while increasing fluence from 0.2 to $2.0 \mathrm{~J} / \mathrm{cm}^{2}$, and rises again up to 0.75 for higher fluences due to high thermal load.

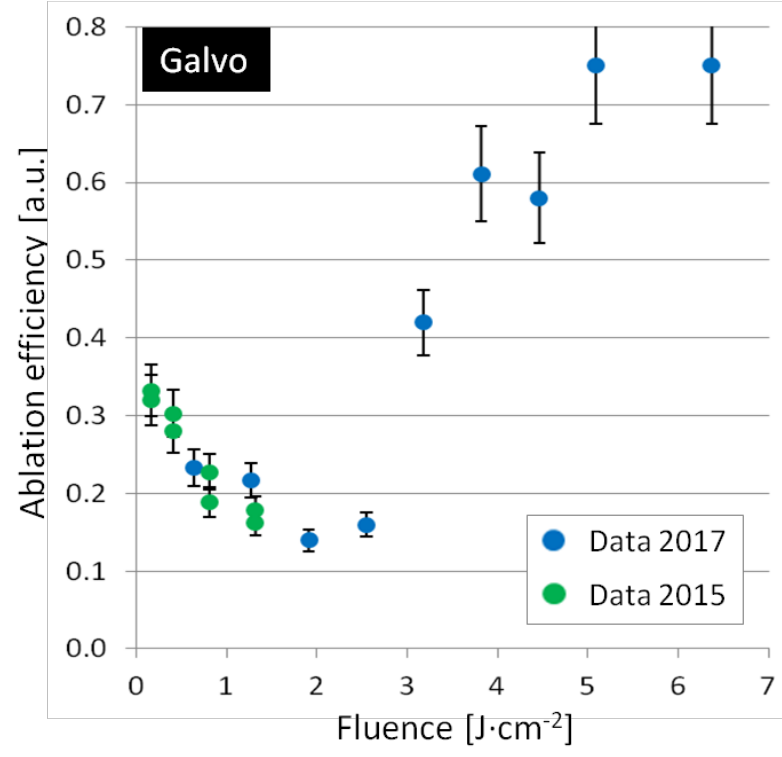

Fig. 1 Ablation efficiency versus fluence $\left[\mathrm{J} / \mathrm{cm}^{2}\right]$ for stainless steel for $500 \mathrm{fs} 2 \mathrm{MHz} 1 \mathrm{~m} / \mathrm{s}$ 1pass. Beam deflection is done by a galvo scanner. Green dots correspond to data obtained in 2015 meanwhile blue dots are related to data obtained in 2017.

The problem is that using high fluences has also a detrimental effect on surface morphology as shown in figure 2. Indeed, melting inside the groove appears above $1.9 \mathrm{~J} / \mathrm{cm}^{2}$, side-burrs appear above $2.6 \mathrm{~J} / \mathrm{cm}^{2}$ and the groove starts to collapse above $3.2 \mathrm{~J} / \mathrm{cm}^{2}$. It is even possible to observe over-thickness inside the groove.

Can we use multipass processing in order to go deep into the target material using such a galvo scanner? To answer this question we have applied up to 120 passes at $5 \mathrm{~m} / \mathrm{s}$ for different average powers ( 9 and $45 \mathrm{~W}$ ) and sets of parameters (fluence, repetition rate). The results in term of ablation efficiency are depicted in figures 3 and 4 . Intermediate levels of fluence and repetition rate lead to the most relevant set of parameters in terms of multipass capability at $9 \mathrm{~W}$ (figure 3, blue dots, $2 \mathrm{MHz} 0.64 \mathrm{~J} / \mathrm{cm}^{2}$ ). In these conditions ablation efficiency drops from 0.37 after 1 pass to 0.15 after 120 passes (60\% loss). Corresponding groove depths are $0.6 \mu \mathrm{m}$ and $39 \mu \mathrm{m}$ respectively. 


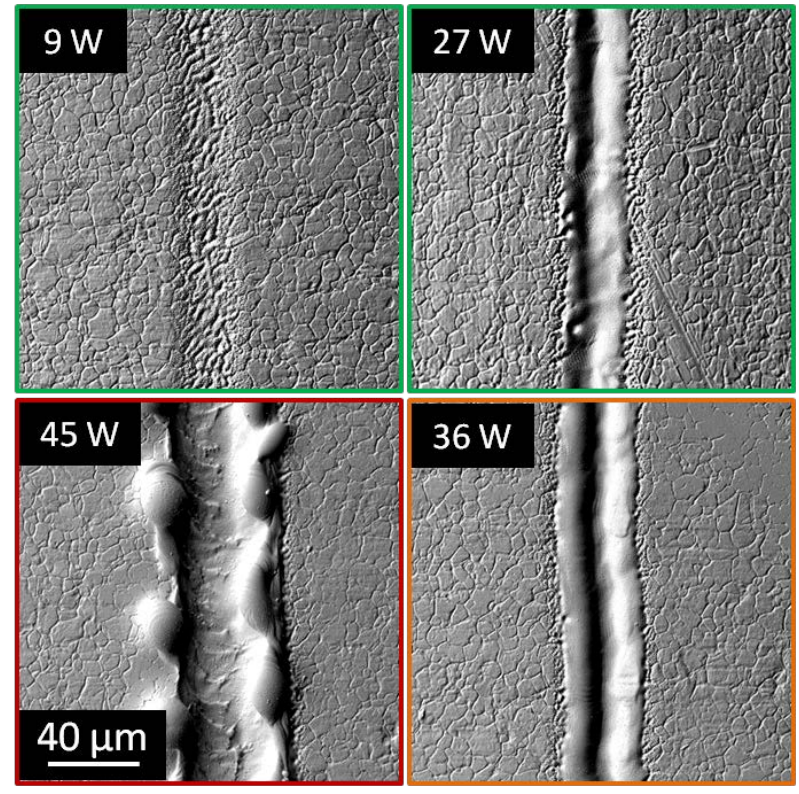

Fig. 2 Surface morphology of stainless steel for $500 \mathrm{fs}$ $2 \mathrm{MHz} 1 \mathrm{~m} / \mathrm{s}$ 1pass for $9 \mathrm{~W} / 0.64 \mathrm{~J} / \mathrm{cm}^{2} ; 27 \mathrm{~W} / 1.9 \mathrm{~J} / \mathrm{cm}^{2}$; $36 \mathrm{~W} / 2.6 \mathrm{~J} / \mathrm{cm}^{2}$ and $45 \mathrm{~W} / 3.2 \mathrm{~J} / \mathrm{cm}^{2}$. Ablation efficiency is $0.23 ; 0.14 ; 0.16$ and 0.42 respectively. Groove exhibits melting above $1.9 \mathrm{~J} / \mathrm{cm}^{2}$ and side-burrs above $2.6 \mathrm{~J} / \mathrm{cm}^{2}$.

If we consider now surface morphology at $9 \mathrm{~W}$, we observe that high fluences $\left(>2 \mathrm{~J} / \mathrm{cm}^{2}\right)$ or high repetition rates $(>4 \mathrm{MHz}$ ) lead to uneven and bumpy grooves probably due to high thermal load (figure 5). The thinner groove observed at $10 \mathrm{MHz}$ can be explained by an insufficient fluence. An acceptable processing quality is obtained for intermediate levels of fluence and repetition rate (figure 5, 2 $\mathrm{MHz} 0.64 \mathrm{~J} / \mathrm{cm}^{2}$ ) even if the corresponding groove exhibits a slight roughness and some evidence of localized melting.

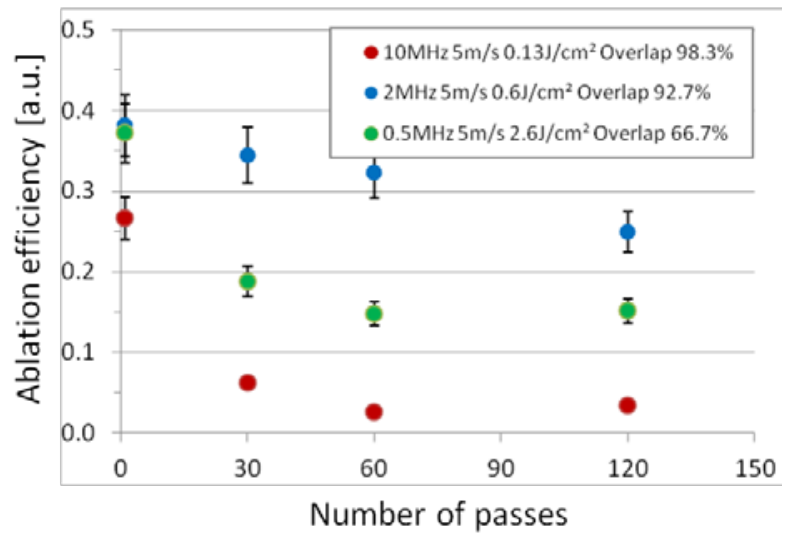

Fig. 3 Ablation efficiency versus the number of passes for different sets of parameters with a galvo scanner at 9W. Scanning velocity is $5 \mathrm{~m} / \mathrm{s}$. For red dots: $10 \mathrm{MHz}$ $0.13 \mathrm{~J} / \mathrm{cm}^{2}$ overlap $98 \%$. For blue dots: $2 \mathrm{MHz} 2.6 \mathrm{~J} / \mathrm{cm}^{2}$ overlap $93 \%$. For green dots: $0.5 \mathrm{MHz} 2.6 \mathrm{~J} / \mathrm{cm}^{2}$ overlap $67 \%$. Corresponding groove depth after 120 passes is 10,39 and $13 \mu \mathrm{m}$ respectively.

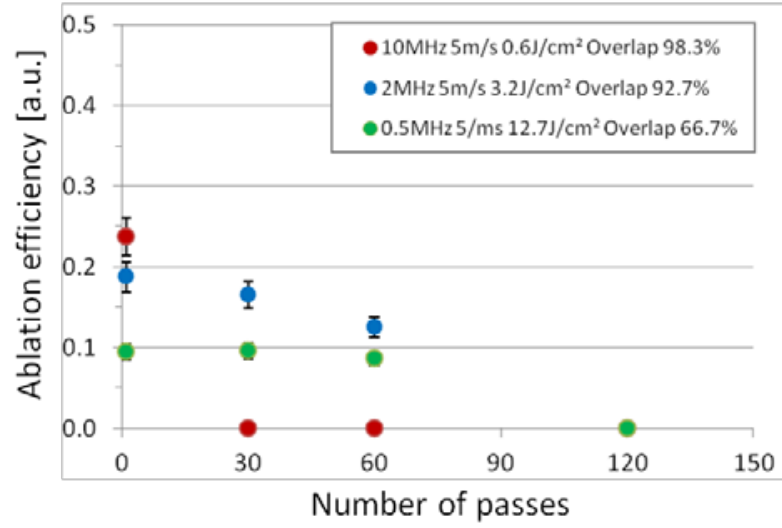

Fig. 4 Ablation efficiency versus the number of passes for different sets of parameters with a galvo scanner at $45 \mathrm{~W}$. Scanning velocity is $5 \mathrm{~m} / \mathrm{s}$. For red dots: $10 \mathrm{MHz} 0.6 \mathrm{~J} / \mathrm{cm}^{2}$ overlap 98\%. For blue dots: $2 \mathrm{MHz} 3.2 \mathrm{~J} / \mathrm{cm}^{2}$ overlap $93 \%$. For green dots: $0.5 \mathrm{MHz} 13 \mathrm{~J} / \mathrm{cm}^{2}$ overlap $67 \%$.
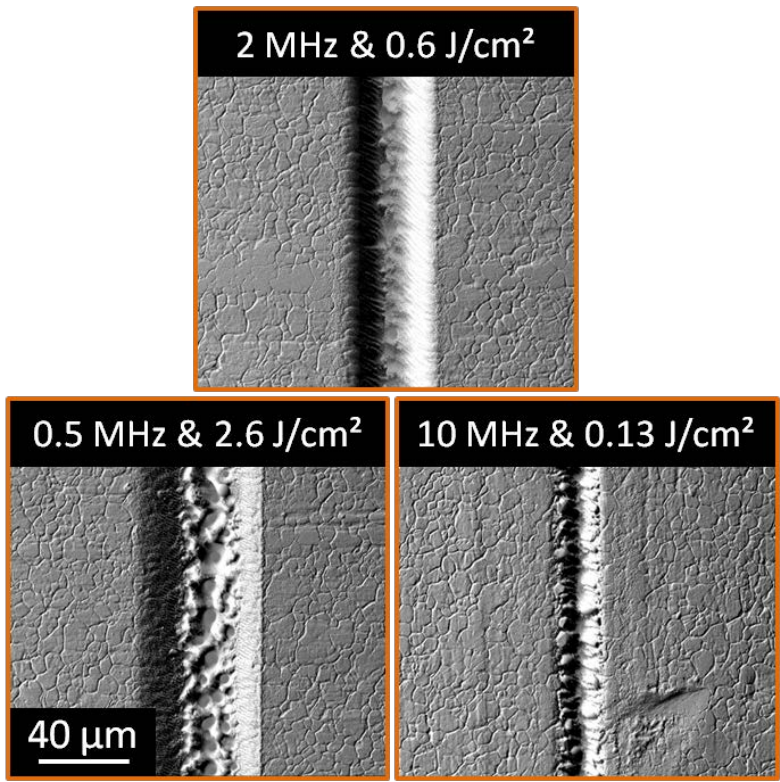

Fig. 5 Surface morphology of stainless steel for $500 \mathrm{fs}$ 9W $5 \mathrm{~m} / \mathrm{s} \quad 120$ passes for $0.5 \mathrm{MHz} / 2.6 \mathrm{~J} / \mathrm{cm}^{2}$; $2 \mathrm{MHz} / 0.6 \mathrm{~J} / \mathrm{cm}^{2}$; and $10 \mathrm{MHz} / 0.13 \mathrm{~J} / \mathrm{cm}^{2}$. Ablation efficiency is 0.15 ; 0.24 ; and 0.03 respectively. Groove depth is 13,39 and $10 \mu \mathrm{m}$ respectively.

\subsection{Ablation efficiency, multipass capability and sur- face morphology with the polygon scanner}

The same protocol is applied with a polygon scanner. Figure 6 shows the variation of ablation efficiency versus fluence at $2 \mathrm{MHz}$ and $25 \mathrm{~m} / \mathrm{s}$. Data are collected after 240 passes since a single pass gives an insufficient depth for a reliable topography measurement. We will see later on that the number of passes has a low influence of ablation efficiency. Due to a lower optical transmission and a larger spot size the maximum fluence is $3 \mathrm{~J} / \mathrm{cm}^{2}$. We notice a sharp improvement of ablation efficiency with increasing fluence from 0.6 to $3 \mathrm{~J} / \mathrm{cm}^{2}$. This behavior is fully different compared to what we obtain with a lower scanning velocity ( $5 \mathrm{~m} / \mathrm{s}$ as depicted in paragraph 3.1), and compared to previous results with a lower repetition rate [16-17]. Thanks to high scanning velocity $(25 \mathrm{~m} / \mathrm{s})$ and low overlap $(67 \%)$ the 
target material can stand the thermal load without detrimental effects on the processing quality as shown in figure 7. This figure presents the surface morphology after 30 and 240 passes at $3 \mathrm{~J} / \mathrm{cm}^{2}$. We observe smooth, burr-free, recast-free and melt-free grooves even for high fluence. So, the surface morphology is fully different compared to the one obtained at a lower scanning velocity with a galvo.

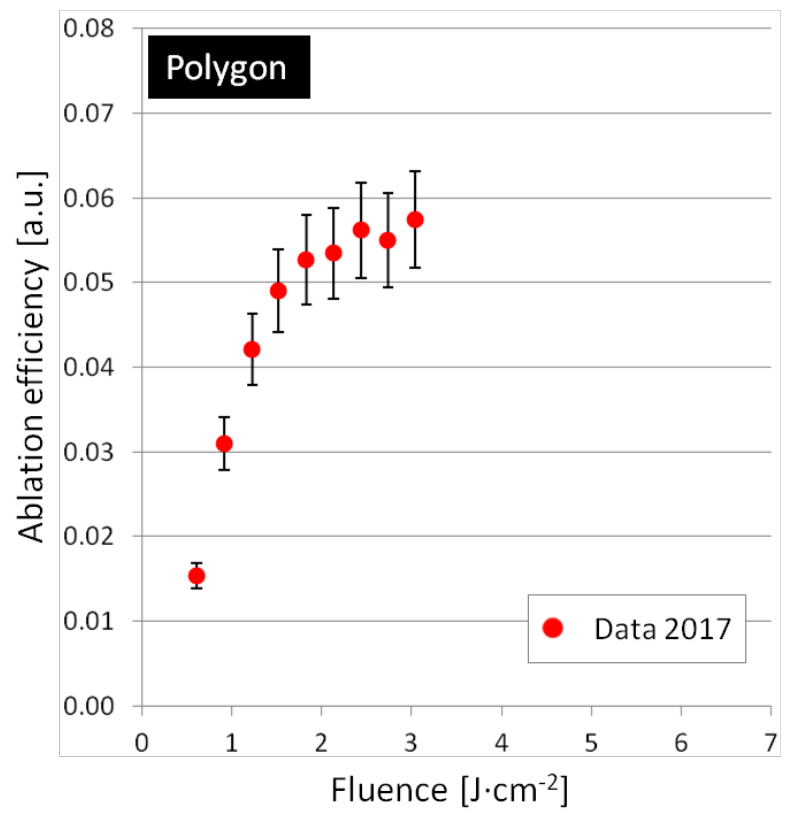

Fig. 6 Ablation efficiency versus fluence $\left[\mathrm{J} / \mathrm{cm}^{2}\right]$ for stainless steel for $500 \mathrm{fs} 2 \mathrm{MHz} 25 \mathrm{~m} / \mathrm{s}$ 240passes. Beam deflection is done owing to a polygon scanner.
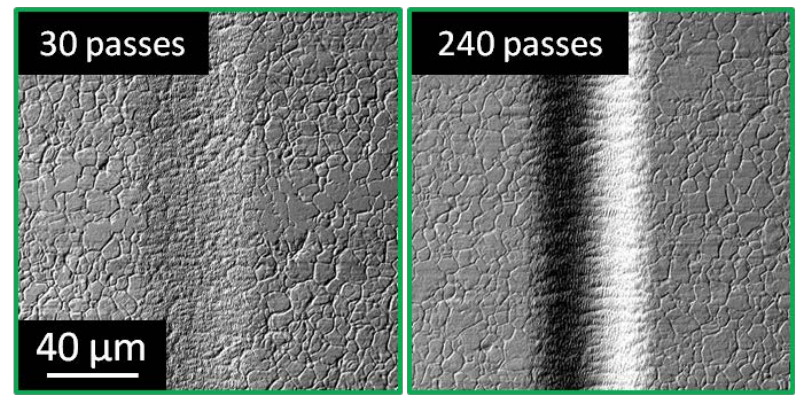

Fig. 7 Surface morphology of stainless steel for $500 \mathrm{fs}$ $2 \mathrm{MHz} 25 \mathrm{~m} / \mathrm{s} 3 \mathrm{~J} / \mathrm{cm}^{2}$ after 30 passes (left) and 240 passes (right).

Figure 8 depicts the evolution of ablation efficiency with increasing number of passes, up to 240 passes at $70 \mathrm{~W}$. Ablation efficiency drops from 0.17 after 30 passes to 0.15 after 240 passes at $10 \mathrm{MHz}$ and $100 \mathrm{~m} / \mathrm{s}$ (12\% loss). It is possible to engrave $40 \mu \mathrm{m}$-deep into the target material at $10 \mathrm{MHz}$ and $25 \mathrm{~m} / \mathrm{s}$. So polygon scanner provides a quite good multipass capability and then enables us to take advantage of the full average power of the $100 \mathrm{~W}$ - femtosecond laser for deep engraving.

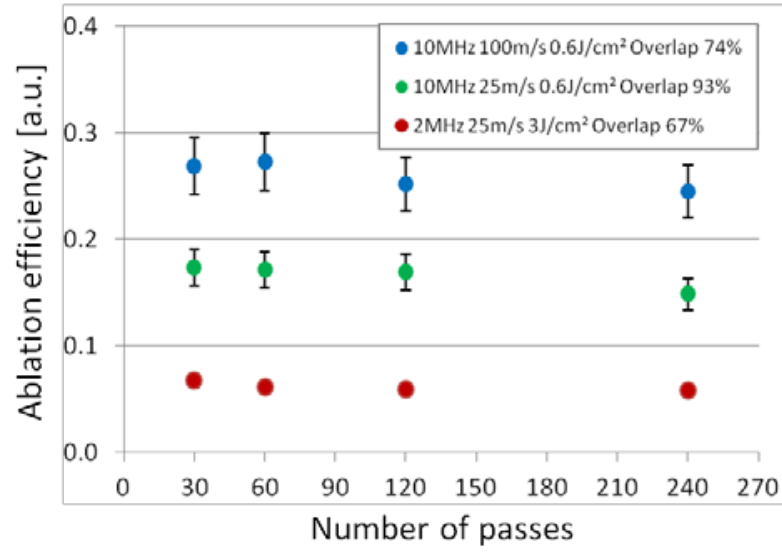

Fig. 8 Ablation efficiency versus the number of passes for different sets of parameters with a polygon scanner at $70 \mathrm{~W}$. For red dots: $2 \mathrm{MHz} 3 \mathrm{~J} / \mathrm{cm}^{2} 25 \mathrm{~m} / \mathrm{s}$ overlap $67 \%$. For green dots: $10 \mathrm{MHz} 0.6 \mathrm{~J} / \mathrm{cm}^{2} 25 \mathrm{~m} / \mathrm{s}$ overlap $67 \%$. For blue dots: $10 \mathrm{MHz} 0.6 \mathrm{~J} / \mathrm{cm}^{2} 100 \mathrm{~m} / \mathrm{s}$ overlap $74 \%$. Corresponding groove depth after 240 passes is 16, 42 and $16 \mu \mathrm{m}$ respectively.
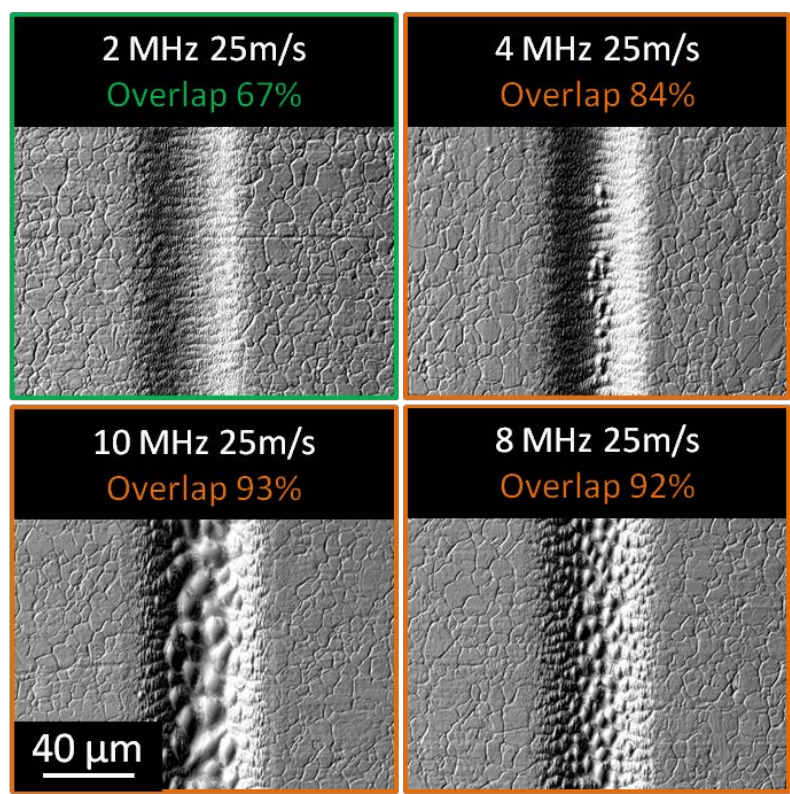

Fig. 9 Surface morphology of stainless steel for 500fs $70 \mathrm{~W} \mathrm{25m/s} \mathrm{120passes} \mathrm{for} 2 \mathrm{MHz}$; $4 \mathrm{MHz} ; 8 \mathrm{MHz}$ and $10 \mathrm{MHz}$. Ablation efficiency is $0.07 ; 0.11 ; 0.12$ and 0.17 respectively. Bumpy surface is always observed for overlap higher than $67 \%$.

As shown in figure 9 the surface morphology is highly dependent on the overlap as well (pulse-to-pulse pitch). If we consider all the trials that we have done (average power $<70 \mathrm{~W}$, repetition rate $<10 \mathrm{MHz}$, fluence $<3 \mathrm{~J} / \mathrm{cm}^{2}$ ), a bumpy surface is always observed for overlap higher than $67 \%$. Below this limit the groove is always smooth, burrfree and melt-free.

Furthermore, rising the repetition rate from 2 to $8 \mathrm{MHz}$ with constant overlap (67\%), cumulative dose $(0.08 \mathrm{~J} / \mathrm{mm})$ and fluence $\left(0.75 \mathrm{~J} / \mathrm{cm}^{2}\right)$ enhances the overall ablation efficiency but also the efficiency of a single pulse as depicted in see table 2. Indeed, ablated volume per pulse is $3 \mu \mathrm{m}^{3}$ at $2 \mathrm{MHz}, 7 \mu^{3}$ at $4 \mathrm{MHz}$ and $17 \mu \mathrm{m}^{3}$ at $8 \mathrm{MHz}$. We assume that this phenomenon belong to heat accumulation that 
occurs when the pulse-to-pulse delay decreases. The consequence is that we may expect detrimental side-effects for higher repetition rate even if the overlap is fixed to $67 \%$. This point has to be considered for up-scaling the process.

Table 2 Ablation efficiency versus repetition rate for constant fluence, constant overlap and constant cumulative dose.

\begin{tabular}{|c|c|c|c|}
\hline Rep. Rate [MHz] & 2 & 4 & 8 \\
\hline Average Power [W] & 17.3 & 34.5 & 70 \\
\hline Fluence $\left[\mathrm{J} / \mathrm{cm}^{2}\right]$ & 0.75 & 0.75 & 0.75 \\
\hline Velocity [m/s] & 25 & 50 & 100 \\
\hline Pulse-to-pulse delay [ $\mu \mathrm{s}]$ & 0.50 & 0.25 & 0.13 \\
\hline Overlap [\%] & 67 & 67 & 67 \\
\hline Number of passes & 120 & 120 & 120 \\
\hline Cumulative dose $[\mathrm{J} / \mathrm{mm}]$ & 0.08 & 0.08 & 0.08 \\
\hline Ablated vol. /pulse & 3 & 7 & 17 \\
\hline Removal Rate $\left[\mathrm{mm}^{3} / \mathrm{min}\right]$ & 0.35 & 1.6 & 8.0 \\
\hline Ablation Efficiency & 0.02 & 0.06 & 0.15 \\
\hline
\end{tabular}

\section{How long to remove $1 \mathrm{~mm}^{3}$ of Steel?}

All these experimental data can be used to estimate the time to remove $1 \mathrm{~mm}^{3}$ of stainless steel. The first criterion is to produce a deep burr-free groove. The second criterion is the overlap; $67 \%$ seems to be a wise choice according to results from the previous paragraph. Then, we have selected one set of parameters with the galvo $(9 \mathrm{~W}, 5 \mathrm{~m} / \mathrm{s}, 0.5$ $\mathrm{MHz}$ ) and another one set with the polygon $(70 \mathrm{~W}, 100 \mathrm{~m} / \mathrm{s}$, $8 \mathrm{MHz}$ ). Corresponding results are regrouped in table 3. The cumulative dose is $0.22 \mathrm{~J} / \mathrm{cm}^{2}$ with the galvo and 0.17 $\mathrm{J} / \mathrm{cm}^{2}$ with the polygon. First of all, we note that whatever the operating parameters with the galvo, there is no way to reduce the processing time below 24 seconds without introducing uncontrolled melting inside the groove and crippling side-effects. Furthermore, we observe that while increasing the average power by a factor of 8 (from 9 to 70 $W$ ), the overall ablation efficiency is decreased by a factor of 2 and then the processing time drops by a factor of 4 , from 24 seconds with the galvo down to 6.3 seconds with the polygon (see table 3 ). So, the results are quite selfconsistent. In addition, we assume that the difference in table 3 in term of ablation efficiency between the galvo and the polygon results comes from the higher fluence used with the galvo scanner. Indeed, ablated volume per pulse is $85 \mu \mathrm{m}^{3}$ at $2.6 \mathrm{~J} / \mathrm{cm}^{2}$ whereas it is $20 \mu \mathrm{m}^{3}$ at $0.75 \mathrm{~J} / \mathrm{cm}^{2}$.

The corresponding surface morphologies for higher number of passes are given in figure 10 in order to compare the processing quality. The behaviors are quite different since we observe an uneven groove at $9 \mathrm{~W}$ with the galvo meanwhile the groove is clean, uniform and perfectly smooth at $70 \mathrm{~W}$ with the polygon. Therefore, this experiment demonstrates that we can handle a $70 \mathrm{~W}$ - femtosecond laser beam and perform efficient engraving of stainless steel provided that the overlap is below $67 \%$ and the repetition is below $8 \mathrm{MHz}$. We assume that this rule of thumb could be useful to scale-up the engraving process using higher average power. We also assume that decreasing the fluence from 2.6 to $0.75 \mathrm{~J} / \mathrm{cm}^{2}$ with a $67 \%$-overlap would enable us to get a smooth and melt-free groove with the galvo, as it is observed with a polygon scanner.

Table 3 Time to remove $1 \mathrm{~mm}^{3}$ of stainless steel using a galvo or a polygon scanner.

\begin{tabular}{|c|c|c|}
\hline Beam deflector device & Galvo & Polygon \\
\hline Average Power [W] & 9.0 & 70 \\
\hline Rep. Rate $[\mathrm{MHz}]$ & 0.5 & 8 \\
\hline Fluence $\left[\mathrm{J} / \mathrm{cm}^{2}\right]$ & 2.6 & 0.75 \\
\hline Velocity $[\mathrm{m} / \mathrm{s}]$ & 5 & 100 \\
\hline Pulse-to-pulse delay [ $\mu \mathrm{s}]$ & 2.0 & 0.13 \\
\hline Overlap [\%] & 67 & 67 \\
\hline Ablated vol. /pulse $\left[\mu \mathrm{m}^{3}\right]$ & 85 & 20 \\
\hline Number of passes & 1 & 30 \\
\hline Removal Rate $\left[\mathrm{mm}^{3} / \mathrm{min}\right]$ & 2.5 & 9.6 \\
\hline Ablation Efficiency & 0.36 & 0.18 \\
\hline Time to remove $1 \mathrm{~mm}^{3}[\mathrm{~s}]$ & 24 & 6.3 \\
\hline
\end{tabular}
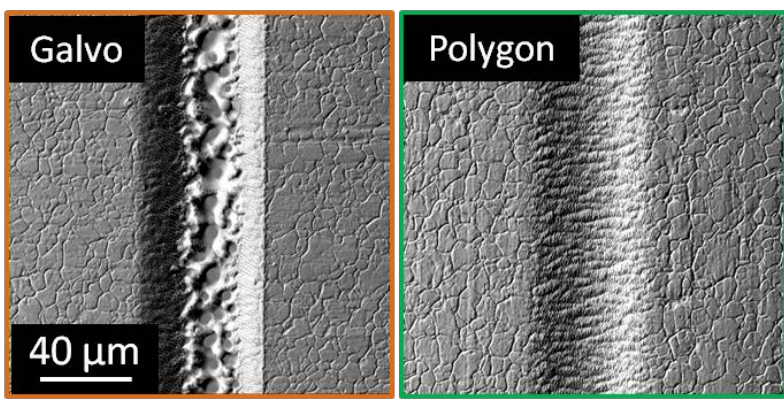

Fig. 10 Surface morphology of stainless steel obtained with galvo (left) and polygon scanner (right). Operating parameters are : 500fs $9 \mathrm{~W} 0.5 \mathrm{MHz} 2.6 \mathrm{~J} / \mathrm{cm}^{2} 5 \mathrm{~m} / \mathrm{s} 120$ passes with galvo (left) and 500fs $70 \mathrm{~W} 8 \mathrm{MHz} 0.75 \mathrm{~J} / \mathrm{cm}^{2}$ $100 \mathrm{~m} / \mathrm{s} 240$ passes with polygon (right). The groove depth is 39 and $9 \mu \mathrm{m}$ respectively. The cumulative dose is $0.22 \mathrm{~J} / \mathrm{cm}^{2}$ with galvo and $0.17 \mathrm{~J} / \mathrm{cm}^{2}$ with polygon.

\section{Conclusion}

We have performed high throughput single and multipass processing of stainless steel with a $100 \mathrm{~W} / 10 \mathrm{MHz}$ ultrashort pulse laser with two different beam deflector devices. On one hand, galvo scanner leads to high ablation efficiency (0.35). The groove is smooth, burr-free and meltfree, provided that the fluence is below $2 \mathrm{~J} / \mathrm{cm}^{2}$ otherwise burr and uncontrolled melting appear. Multipass processing capability has been demonstrated up to $9 \mathrm{~W}$ but not acquired for higher average power. On the other hand, polygon scanner leads to lower ablation efficiency but upscaling has been demonstrated up to $70 \mathrm{~W}$ with an outstanding processing quality provided that the overlap is below $67 \%$ and the repetition is below $8 \mathrm{MHz}$, which correspond to a $12.5 \mu \mathrm{m}$ - pulse-to-pulse pitch and a $0.13 \mu \mathrm{s}-$ pulse-to-pulse delay. The point is not to avoid heat accumulation but to take advantage of this phenomenon as long as the target material can stand the thermal load without detrimental effects on the processing quality. Multipass processing has been successfully demonstrated at $70 \mathrm{~W}$. 


\section{Acknowledgments}

We acknowledge the European Commission, the French Government and the Aquitaine Regional Council for support and funding.

\section{References}

[1] L. Shah, M. Fermann, J. Dawson, and P. Barty: Opt. Express, 14, (2006) 12546.

[2] B.N. Chichkov, C. Momma, S. Nolte, F. Von Alvensleben, and A. Tünnermann: Appl. Phys. A, 63, (1996) 109.

[3] C. Momma, B.N. Chichkov, S. Nolte, F. Von Alvensleben, A. Tünnermann, H. Welling, and B. Wellegehausen: Opt. Com., 129, (1996) 134.

[4] P. Russbueldt, T. Mans, J. Weitenberg, H.D. Hoffmann, and R. Poprawe: Opt. Lett., 35, (2010) 4169.

[5] T. Eidam, S. Hanf, E. Seise, T.V. Andersen, T. Gabler, C. Wirth, T. Schreiber, J. Limpert, and A. Tünnermann: Opt. Lett., 35, (2010) 94.

[6] H. J. Otto, F. Stutzki, N. Modsching, C. Jauregui, J. Limpert, and A. Tünnermann: Opt. Lett., 39, (2014) 6446.

[7] C. Hönninger, and J. Akhil: Laser Technik Journal, 02, (2016) 56.

[8] U. Loeschner, J. Schille, A. Streek, T. Knebel, L. Hartwig, R. Hillmann, and C. Endisch: Proc. ICALEO, (2015) M1208.

[9] S.S. Wellershoff, J. Hohlfeld, J. Güdde, and E. Matthias: Appl. Phys. A, 69, (1999) S99.

[10] J. Byskov-Nielsen, J.M. Savolainen, M.S. Christensen, and P. Balling: Appl. Phys. A, 103, (2011) 447.

[11]S. I. Anisimov, and B. S. Lukyanchuk: Phys.-Usp., 45, (2002) 293.

[12] A.Y. Vorobyev, and C. Guo: Appl. Phys. Lett., 86, (2005) 011916.

[13]A.Y. Vorobyev, and C. Guo: Opt. Express, 14, (2006) 13113.

[14]F. Bauer, A. Michalowski, T. Kiedrowski, and S. Nolte: Opt. Express, 23, (2015) 001035.

[15] R. Le Harzic, D. Breitling, M. Weikert, S. Sommer, C. Föhl, S. Valette, C. Donnet, E. Audouard, and F. Dausinger: Appl. Surf. Sci., 249, (2005) 322.

[16] J. Lopez, M. Faucon, R. Devillard, Y. Zaouter, C. Hönninger, E. Mottay, and R. Kling: J. Laser Micro/Nanoengin., 10 (2015).

[17] J. Lopez, G. Mincuzzi, R. Devillard, Y. Zaouter, C. Hönninger, E. Mottay, and R. Kling: J. Laser Appl., 27, (2015) S28008.

[18]B. Neuenschwander, B. Jaeggi, and M. Schmid: Phys. Proc., 41, (2013) 794.

[19]B. Neuenschwander, B. Jaeggi, M. Schmid, and G. Hennig: Phys. Proc., 56, (2014) 1048.

[20]A. Ancona, S. Döring, C. Jauregui, F. Röser, J. Limpert, S. Nolte, and A. Tünnermann: Opt. Lett., 34, (2009) 3304.

[21]J. König, S. Nolte, and A. Tünnermann: Opt. Express, 13, (2005) 10597.

[22] J. Finger, C. Kalupka, and O. Nottrodt: Proc. ICALEO, (2015) M303.
[23]F. Di Niso, C. Gaudiuso, T. Sibillano, F.P. Mezzapesa, A. Ancona, and P.M. Lugarà: Opt. Express, 22 (2014) 012200.

[24]B. Neuenschwander, B. Jaeggi, M. Zimmermann, V. Markovic, B. Resan, K. Weingarten, R. de Loor, and L. Penning: J. Laser Appl., 28, (2016) 022506.

[25]C. Kerse, H. Kalaycroglu, P. Elahi, B. Cetin, D. Kesim, Ö. Akçaalan, S. Yavas, M. Asik, B. Öktem, H. Hoogland, R. Holzwarth, and F. Ö. Ilday, Nature, 537, (2016) 84.

[26] M.W. Chase, Jr.: NIST - JANAF Thermochemical Tables, 4th Ed., J. Phys. Chem. Ref. Data, 9, (1998) 1.

[27]L.V. Zhigilei, Z. Lin and D.I. Ivanov: J. Phys. Chem. C, 113, (2009) 11892.

(Received: June 30, 2017, Accepted: November 29, 2017) 